\title{
Correction to: Toward clinically usable CAD for lung cancer screening with computed tomography
}

\author{
Matthew S. Brown ${ }^{1} \cdot$ Pechin Lo ${ }^{1}$. Jonathan G. Goldin ${ }^{1} \cdot$ Eran Barnoy ${ }^{1} \cdot$ Grace Hyun J. Kim ${ }^{1} \cdot$ Michael F. McNitt-Gray ${ }^{1} \cdot$ \\ Denise R. Aberle ${ }^{1}$
}

Published online: 14 November 2019

(C) European Society of Radiology 2019

Correction to: Eur Radiol (2014) 24:2719-2728

https://doi.org/10.1007/s00330-014-3329-0

The original version of this article, published on 24 July 2014, unfortunately contained a mistake. In section "Discussion," a sentence was worded incorrectly. The correct wording is the following: "In the NLST, a 4-mm size threshold yielded a positive screen rate of $24.2 \%$, with a $96.4 \%$ false discovery rate."

The online version of the original article can be found at https://doi.org/ 10.1007/s00330-014-3329-0

Matthew S. Brown

mbrown@mednet.ucla.edu

1 Center for Computer Vision and Imaging Biomarkers, Department of Radiological Sciences, David Geffen School of Medicine at UCLA, 924 Westwood Blvd., Suite 615, Los Angeles, CA 90024, USA 